\title{
Aberrant expression of miRNAs predicts recurrence and survival in stage-II colorectal cancer patients from Egypt
}

\author{
Abeer A. Bahnassy", Mohammad El-Sayed, Nasr M. Ali, Ola Khorshid, Marwa M. Hussein, Hend F. Yousef, \\ Marwa A. Mohanad, Abdel-Rahman N. Zekri and Salem E. Salem
}

\begin{abstract}
Background: Patients with stage II CRC have a varying survival outcome. Therefore, it is critical to identify prognostic biomarkers that can define more aggressive forms of the disease. We assessed the expression levels of five miRNAs that have been previously addressed in relation to the development and progression of solid and hematological tumors.

Methods: We measured the expression levels of miR-21, miR-137, miR-145, miR-320 and miR-498in stage II CRC patients from Egypt (124 tissues and 41 blood samples) by quantitative real time PCR (qPCR). The results were correlated with relevant clinicopathological factors, response to treatment and survival rates of the patients.

Results: miR-137, miR-145 and miR-320 were significantly reduced in 39.5\%, 48.4\% and 52.4\%; respectively whereas miR-21 and miR-498 were significantly overexpressed in $48.4 \%$ and $40.3 \%$ of the CRC tissues compared to the control group. In patients' blood, miR-137, miR-145 and miR-320 were significantly reduced in $46.3 \%, 46.3 \%$ and 51 . 2\%; respectively whereas mir-21 and miR-498 were significantly overexpressed in $46.3 \%$ and $43.9 \%$ of the cases, respectively. The concordance between tissue and blood was weak for miR-320 and miR-145 (kappa 40-65\%), intermediate for miR-498 and miR-137 (kappa 65-75\%) and strong for miR-21 (kappa 75-85\%). In univariate analysis performance status, over-expression of miR-21 and miR-498 and reduced miR-137, miR-145, and miR-320 associated significantly with reduced DFS and OS. However, in multivariate analysis, miR-498 and miR-320 were independent prognostic factors for DFS whereas miR-21 was independent prognostic factors for OS.
\end{abstract}

Conclusions: miRNAs play an important role in the development and progression of stage II CRC. A five markers panel (miR-21, miR-498, miR-137, miR-145 and miR-320) can predict recurrence and survival in stage II CRC patients from Egypt.

Keywords: Colorectal cancer, Stage II, miRNA, Survival, Response to treatment

\section{Background}

Colorectal cancer (CRC) accounts for about $9.7 \%$ of all cancers worldwide and it is the second most common cause of cancer-related death worldwide [1]. Stage II CRC represents a peculiar state because surgically treated; stage II CRC patients usually have a 5-year survival of $75 \%-80 \%$. Despite the success of curative surgery for localized disease, $20-25 \%$ of stage II patients can develop recurrence and dye from the disease. Currently,

\footnotetext{
* Correspondence: chaya2000@hotmail.com

Pathology Department, National Cancer Institute, Tissue Culture and Cytogenetics Unit, Cairo, Egypt
}

it is not possible to differentiate between stage II CRC patients with good or poor prognosis based on the traditional clinicopathological factors alone [2]. Therefore it is essential to find new individually-based, genetic biomarkers that can categorize patients according to their treatment outcome and to determine which patients should receive therapy [2].

The microRNAs are small, non-coding, single stranded RNA molecules of approximately 22 nucleotides in length. They represent important regulators of gene expression in cancer cells [3]. According to literature, more than $50 \%$ of the human protein-coding genes are 
regulated by miRNAs including a significant number of oncogenes and tumor suppressor genes [4]. miRNAs are involved in the regulation of several basic biological cellular processes including proliferation, apoptosis, angiogenesis, immune response and hormone secretion. Thus, they can be used as prognostic and predictive factors in the clinical setting [5].

Previous studies showed that miRNAs are differentially expressed in normal and neoplastic colonic tissues and therefore changes in their expressions contribute to the development and progression of CRC. Aberrant expression of certain miRNAs that mediate cell growth and tumor progression have been reported in CRC cases from Europe and USA using different miRNA microarray assays. Among these are miR-21, miR-137, $m i R-145, m i R-320$ and $m i R-498[6,7]$.

$m i R-21$ overexpression induces invasion, intravasation, metastasis and apoptosis via downregulation of the programmed cell death 4 (PDCD4), which is a known tumor suppressor whereas miR145 down-regulates the insulin receptor substrate-1 (IRS-1) protein, which is a mitogenic, anti-apoptotic, and anti-differentiation factor $[8,9]$.

A recent study by Sheng et al., [10] showed significant decrease of miR-145 in colon cancer cell lines as well as in CRC tissues (especially cases with lymph node or distant metastasis) compared to the non-cancerous mucosal tissues suggesting a tumor suppressor effect of this miRNA. Similarly, the few available studies regarding miR-137 showed down-regulation of this miRNA in colonic adenomas and carcinomas. In a recent study, Chen et al., [11], demonstrated that all the CRC cases tested (18) had reduced miR-137 expression and this reduction correlates with tumor progression and metastasis confirming the protective effect of $m i R-137$ in colorectal carcinogenesis. This inhibitory effect of miR137 is achieved mainly through controlling cell proliferation, migration, invasion and colony formation, which consequently inhibits tumor growth and metastasis. The miR-320 is also down regulated in CRC tissues whereas its expression suppresses CRC development through targeting SOX4, FOXM1, and FOXQ1 genes [12].

miR-498, is a non-coding miRNA which is located inter- genetically in $19 \mathrm{q} 13.41$. It targets several genes involved in the control of cellular growth. Gopalan et al., [5] assessed miR-498 expression in colon cancer cell lines as well as in $60 \mathrm{CRCs}$ and 20 non-neoplastic colonic tissues. They found that, miR-498 expression was too low to be detected in all CRC cases compared to the non-neoplastic tissues suggesting a protective role for this miRNA in colonic carcinogenesis however, no study was done since then to confirm this issue.

Till now, there is no published data from Egypt or the Middle East regarding the frequency and patterns of aberrant miRNAs expression and their contribution to the development and progression of CRC. Therefore, we sought to assess the expression levels of the aforementioned miRNA panel (miR-21, miR-137, miR-145, miR-320 and $m i R-498)$ in a well characterized group of stage II CRC patients from Egypt and to determine their possible prognostic and/or predictive value.

\section{Methods}

\section{Patients}

The study included 124 patients with stage II colorectal cancer (CRC) who were diagnosed and treated in the National Cancer institute, Cairo University during the period from January 2004 till December 2014 (the retrospective group). Blood samples were freshly obtained from another 41 patients (the prospective group) to assess the concordance between tissue and serum levels of the studied miRNAs. All samples used in the study were obtained prior to treatment. Pooled blood from 20 normal healthy subjects and 41 histologically-confirmed, normal colonic mucosal tissues obtained from the normal mucosa adjacent to surgically removed nonneoplastic lesions of the colon were used as blood and tissue control, respectively. A written informed consent was obtained from all participants prior to enrollment in the study, and the Institutional Review Board (IRB) of the NCI approved the study protocol which was in accordance with the 2011 Declaration of Helsinki. All demographic and relevant clinic-pathological features of the CRC patients are summarized in Table 1.

\section{Blood and tissue samples}

Ten milliliters blood were prospectively collected from 41 patients and 20 normal control subjects in a serum vacutainer tube, centrifuged at $3000 \mathrm{rpm}$ for $10 \mathrm{~min}$ at $4{ }^{\circ} \mathrm{C}$ to remove the cellular components. The supernatant was then collected and stored at $-80{ }^{\circ} \mathrm{C}$ until used. Paraffin blocks for stage II CRC cases were also obtained from the archive of the Pathology department of the NCI, Cairo University. From each tumor and normal tissue paraffin block, $5 \mu \mathrm{m}$-thick sections (7-10 sections) were cut into a $2 \mathrm{~mL}$ sterile, plastic Eppendorf tube for miRNA extraction.

\section{Treatment and follow up of the patients}

Adjuvant treatment (either pre- or post- operative) was given to 90 patients (72.6\%), radiotherapy was given to 43 (34.7\%) and chemotherapy to 75 (60.5\%) (Table 2). Chemotherapy was given either as capecitabine $(2 \mathrm{~g} / \mathrm{m} 2$ daily for 14 days every 21 days for 8 cycles) or as Roswell park regimen with Leucovorin $(500 \mathrm{mg} / \mathrm{m} 2$ iv over $2 \mathrm{~h}$ ) and fluorouracil $500 \mathrm{mg} / \mathrm{m} 2$ iv bolus $1 \mathrm{~h}$ after the start of leucovorin once weekly for 6 weeks every 8 weeks repeated for 3 cycles. Radiotherapy was given concomitantly with chemotherapy (CCRT) to patients with lower 
Table 1 Clinicopathological features of the patients

\begin{tabular}{|c|c|}
\hline Features & Number (\%) \\
\hline \multicolumn{2}{|l|}{ Age (yrs) } \\
\hline$\leq 45$ & $60(48.4 \%)$ \\
\hline$>45$ & $64(51.6 \%)$ \\
\hline \multicolumn{2}{|l|}{ Gender } \\
\hline Male & $64(51.6 \%)$ \\
\hline Female & $60(48.4 \%)$ \\
\hline \multicolumn{2}{|l|}{ Residence } \\
\hline Urban & $66(53.2 \%)$ \\
\hline Rural & $58(48.4 \%)$ \\
\hline \multicolumn{2}{|l|}{ Family history } \\
\hline -ve & $103(83.1 \%)$ \\
\hline+ ve & $21(16.9 \%)$ \\
\hline \multicolumn{2}{|l|}{ Smoking } \\
\hline -ve & $88(71.0 \%)$ \\
\hline+ ve & $36(29.0 \%)$ \\
\hline \multicolumn{2}{|l|}{ PS } \\
\hline 0 & $56(45.2 \%)$ \\
\hline 1 & $48(38.7 \%)$ \\
\hline$\|$ & $20(16.1 \%)$ \\
\hline \multicolumn{2}{|l|}{ Pathology } \\
\hline Adenocarcinoma & $105(84.7 \%)$ \\
\hline Mucinous adenocarcinoma & $19(15.3 \%)$ \\
\hline \multicolumn{2}{|l|}{ Grade } \\
\hline$|-| \mid$ & $109(87.9 \%)$ \\
\hline III & $15(12.1 \%)$ \\
\hline \multicolumn{2}{|l|}{ T. stage } \\
\hline T3 & $84(67.7 \%)$ \\
\hline T4 & $32(25.8 \%)$ \\
\hline Missed & $8(6.5 \%)$ \\
\hline \multicolumn{2}{|l|}{ Dissected LN } \\
\hline$<12$ & $60(48.4 \%)$ \\
\hline$\geq 12$ & $64(51.6 \%)$ \\
\hline \multicolumn{2}{|l|}{ Adjuvant } \\
\hline No & $30(24.2 \%)$ \\
\hline Yes & $94(75.8 \%)$ \\
\hline \multicolumn{2}{|l|}{ Toxicity } \\
\hline No & $69(41.5)$ \\
\hline Yes & $55(58.5 \%)$ \\
\hline
\end{tabular}

rectal cancer either pre or postoperatively (50.4 Gy over 28 settings). Adjuvant chemotherapy was given to high risk patients e.g. patients with obstruction, perforation, T4 disease or inadequate LN dissection $(<12)$, elevated pretreatment CEA, vascular invasion, perineural invasion or positive circumferential radial margin (CRM). Adjuvant
Table 2 The treatment given to the patients and the related toxicity

\begin{tabular}{ll}
\hline Treatment given or toxicity & No (\%) \\
\hline Perioperative CCRT & $81(65.3)$ \\
No & $43(34.70$ \\
Yes & \\
Adjuvant CTH & $49(39.5)$ \\
No & $75(60.5)$ \\
Yes & \\
Surgery alone & $30(24.2)$ \\
$\quad$ Yes & \\
Toxicity of treatment & $55(58.5)$ \\
$\quad$ Yes & \\
Treatment related deaths & $4(4.3)$ \\
$\quad$ Yes &
\end{tabular}

CCRT concomitant chemoradiotherapy, CTH chemotherapy

chemotherapy was given for 4-6 months guided by tolerance and compliance). The most common toxicities reported with chemotherapy were diarrhea, cytopenias mainly neutropenia, elevated liver enzymes, nausea and vomiting. Treatment related deaths occurred in $4.3 \%$ only of patients who received treatment. The median follow-up period was 27 months. Local recurrence and distant metastases were assessed then, disease- free (DFS) and overall survival (OS) rates were calculated.

\section{MicroRNA extraction from sera and tissues}

miRNAs were extracted from tissue and serum samples of the patients and control subjects using the miRNeasy kit for FFPE and miRNeasy mini kit for blood (both from Qiagen, Germany); respectively according to manufacturer's instructions. The concentrations and purity of the miRNAs were determined using the Nanodrop 1000 spectrophotometer (Nanodrop Technologies Inc., USA).

\section{Quantitative real-time polymerase chain reaction (qRT-PCR)} The expression levels of $m i R-21, m i R-137, m i R-145$, $m i R-320$ and $m i R-498$ were assessed in serum and tissue samples in triplicates using the TaqMan miRNA Assay (Applied Biosystems, Inc., Foster City, CA, USA. The reverse transcriptase reaction included $10 \mathrm{ng}$ total RNA $(5 \mu \mathrm{l}), 0.15 \mu \mathrm{l} d N T P s$ (100 mM total), $1.0 \mu \mathrm{l}$ Multiscribe RT enzyme $(50 \mathrm{U} / \mu \mathrm{l}), 0.19 \mu \mathrm{l}$ RNase Inhibitor $(20 \mathrm{U} / \mu \mathrm{l})$, $1.5 \mu \mathrm{l}$ 10XRT buffer, $4.16 \mu \mathrm{l}$ nuclease free water (SigmaAldrich, Ayshire, UK) and $3.0 \mu \mathrm{l}$ 5XRT Primer. The total volume of the reaction was $15 \mu \mathrm{l}$. The amplification reactions were done using a GeneAmp PCR System 9700 thermal cycler (Applied Biosystems). All reactions were first incubated at $61{ }^{\circ} \mathrm{C}$ for $35 \mathrm{~min}$ and then at $42{ }^{\circ} \mathrm{C}$ for 
$30 \mathrm{~min}$, followed by an inactivation step of $55{ }^{\circ} \mathrm{C}$ for 5 min. Quantitative PCR amplification of the cDNAs was performed using sequence-specific primers from the TaqMan MicroRNA Assay Human Panel (Applied Biosystems). The $20 \mathrm{ul}$ of the PCR included 10ul of the universal PCR Master Mix (no AmpErase UNG), 2ul of each TaqMan MicroRNA Assay Mix and 1.5ul RT product and $6.5 \mathrm{ul} \mathrm{H}_{2} \mathrm{O}$. The amplification program was as follows: $95{ }^{\circ} \mathrm{C}$ for $9 \mathrm{~min}$, followed by 40 cycles of $95{ }^{\circ} \mathrm{C}$ for $15 \mathrm{~s}$ and $60{ }^{\circ} \mathrm{C}$ for $1 \mathrm{~min}$. To correct for the variability among different samples, the expression level of a target miRNA was normalized to the expression levels of two different reference genes (as genes found stably expressed across most of the samples): RNU6B (RNU6$6 \mathrm{P})$ and $m i R-16$. Then the miRNA expression was normalized using the snRNA-U6 as an internal control. The $\Delta \mathrm{Ct}$ method was used to calculate the relative expression levels and the expression level of each miRNA was compared in tumor and normal tissue samples as well as in the recurrent and non-recurrent cases.

\section{Statistical analysis}

SPSS for windows, version 21 (IBM, Armonk, Ny, USA) was used for analysis. Numerical data are expressed as mean \pm SD or median and ranges. Categorical data was measured as percentages. We compared the expression level of studied miRNA between recurrent and nonrecurrent cases using Chi Square $\left(x^{2}\right)$ test. The relative expression level of studied miRNAs was presented in box plots and compared using Mann-Whitney. As a measure of reliability Cohen's Kappa was used to assess the degree of agreement between blood and tissue samples. Kappa should be greater than $0.7(70 \%)$ and not to only be significant $(p<0.05)$. Kappa more than 0.4 was considered fair. The association with survival was analyzed using Kaplan-Meier analysis and curves were compared using the log-rank test and Cox regression analysis was used to adjust for other prognostic indicators. All $p$. values were two sided and $p$. value $<0.05$ was considered significant.

\section{Results}

\section{Patient's characteristics}

The mean age of the patients was $49.7 \pm 13.2$ (median: 48 ; range $19-78$ years). The male to female ratio was 1.07:1 and more than half of patients were residing in urban areas. A positive family history of malignancy was reported in $17 \%$ of the cases and one third of patients were smokers. Most of the cases had good performance status (ECOG 0\&I) and 16\% had PSII. Rectal cancer constituted $33 \%$ of the cases with the lower third being the dominant site. Right and left colonic cancers were almost equal in frequency (30\%, each) and adenocarcinoma was the predominant histological subtype (84.7\%).
At diagnosis, $67.7 \%$ of the patients had T3 tumors and $25.8 \%$ had T4 tumors. More than $50 \%$ of the cases underwent adequate lymph node dissection $(\geq 12), 86.3 \%$ of the cases were grade 2 followed by $11.3 \%$ grade 3 (Table 1). The most common toxicities reported with chemotherapy were diarrhea, cytopenias mainly neutropenia, elevated liver enzymes, nausea and vomiting. Treatment- related deaths occurred in $4.3 \%$ only of the patients who received treatment (Table 2).

\section{Differential expression of the studied miRNAs in tissues and sera of the patients}

The expression levels of all tested miRNAs in the neoplastic cases (serum\& tissues) compared to the normal control samples are illustrated in Table 3 and Fig. 1. Aberrant expression of the five studied miRNAs was present in $88 / 124(71 \%)$ of the CRC tissues and in $30 / 41$ (73.2\%) of the serum samples compared to the normal control. Increased expression of $m i R-21$ and $m i R-498$ were reported in 60 (48.4\%) and 50 (40.3\%) CRC tissue samples compared to 19 (46.3\%) and 18 (43.9\%) serum samples; respectively. Reduced tissue expression of $m i R$ 137, $m i R-145$ and $m i R-320$ were present in 49 (39.5\%), $60(48.4 \%)$ and 65 (52.4\%) cases. Reduced serum levels of $m i R-137, m i R-145$ and $m i R-320$ were present in 19 (46.3\%), 19 (46.3\%) and 21 (51.2\%) cases; respectively (Fig. 2a \& b). The concordance between serum and tissues for all tested miRNA was highly statistically significant $(\boldsymbol{p}<\mathbf{0 . 0 0 1}$; for all).

\section{The degree of concordance between the expression levels of the studied miRNAs in CRC patients}

The concordance (measure of agreement) between serum and tissue miRNAs in the prospective samples was strong for $m i R-21$ [Measure of agreement-Kappa-80.2\%] and $m i R$ 137 [Measure of agreement-Kappa-70.1\%], intermediate for $m i R N A-498$ [Measure of agreement- Kappa-69.9\%] and miR-137 [Measure of agreement- Kappa-70.1\%], but weak for $m i R-145$ and $m i R-320$ [Measure of agreement- Kappa$50 \% \& 41 \%$; respectively]. The degree of concordance between the expression levels of different miRNAs was weak except between $m i R-21$ and $m i R-320$ (intermediate) (Tables 4 \& 5).

The correlation between aberrant miRNAs expression and patients' characteristics

No significant association was found between patients characteristics and the expression levels of the tested miRNAs, except for the correlation between the incidence of recurrence and aberrant miR-137, $m i R-145$, and $m i R-498$ expressions $(p<0.001, p=0.02$ and $p<0.001$; respectively) (Table 6). 
Table 3 miRNAs expression levels in sera and tissues of CRC patients and normal control subjects

\begin{tabular}{|c|c|c|c|c|}
\hline miRNAs assessed & CRC tissue $(n=124)(\%)$ & Statistics & CRC serum $(n=41)(\%)$ & Statistics \\
\hline miRNA-498 & & $x^{2}=12.4$ & & $x^{2}=12.5$ \\
\hline Normal & $74(59.7)$ & $P<0.001$ & 23(56.1) & $P<0.001$ \\
\hline Over-expressed & $50(40.3)$ & & $18(43.9)$ & \\
\hline miRNA-21 & & $x^{2}=16.6$ & & $x^{2}=13.5$ \\
\hline Normal & $64(51.6)$ & $P<0.001$ & $22(53.7)$ & $P<0.001$ \\
\hline Over-expressed & $60(48.4)$ & & $19(46.3)$ & \\
\hline miRNA -145 & & $x 2=16.6$ & & $x^{2}=13.5$ \\
\hline Normal & $64(51.6)$ & $P<0.001$ & $22(53.7)$ & $P<0.001$ \\
\hline Down-expressed & $60(48.4)$ & & $19(46.3)$ & \\
\hline miRNA -137 & & $x^{2}=11.9$ & & $x^{2}=13.5$ \\
\hline Normal & $75(60.5)$ & $P<0.001$ & $22(53.7)$ & $P<0.001$ \\
\hline Down-expressed & 49 (39.5) & & $19(46.3)$ & \\
\hline miRNA -320 & & $x 2=19.1$ & & $x^{2}=15.6$ \\
\hline Normal & $59(47.6)$ & $P<0.001$ & $20(48.8)$ & $P<0.001$ \\
\hline Down-expressed & $65(52.4)$ & & $21(51.2)$ & \\
\hline
\end{tabular}

The data in boldface denotes the presence of statistically significant difference between the studied groups

\section{Survival analysis}

During the follow up period 54 patients (43.5\%) died. The median overall survival (OS) for the patients was 27 months (range: 3-152 months) and the median time of disease free survival (DFS) was 24 months (range: $3-152$ ). The 5 years DFS was $60.2 \%$ and the 10 years DFS was $45.6 \%$. The 5 years OS was $69.1 \%$ and the 10 years OS was $56.5 \%$. None of the patients' characteristics had an impact on DFS or OS except for the performance status. Patients with ECOG PS-0 had significantly better DFS and OS compared to those with ECOG PS-I\&II $(p=0.016 \& p=0.005$; respectively). Adjuvant therapy given to patients did not improve DFS or OS significantly and treatment

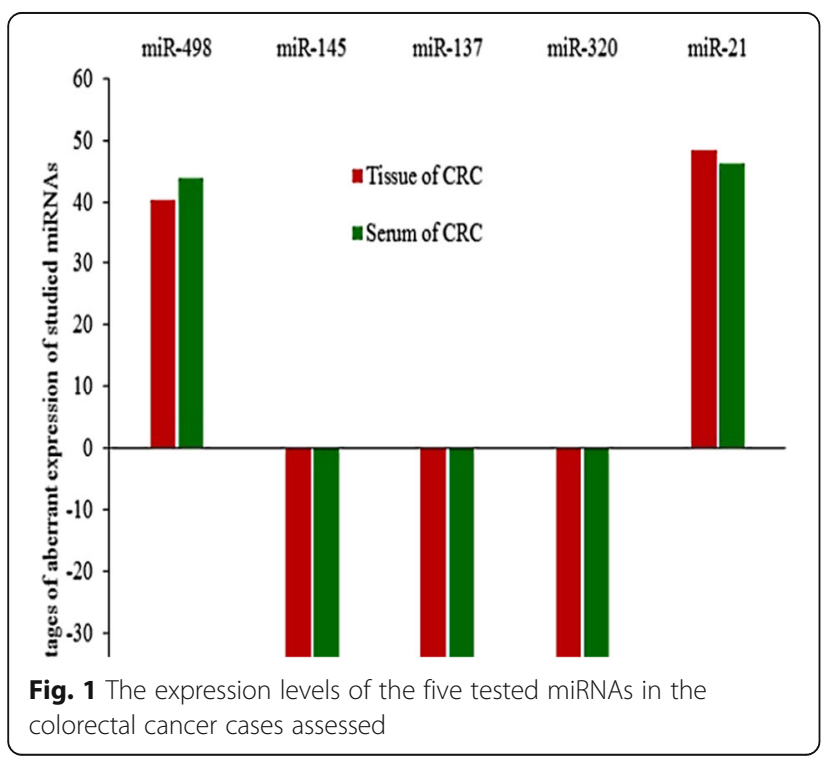

related toxicities did not associate with significantly worse DFS or OS (Tables 7 \& 8) (Figs. 3 \& 4). Kaplan-Meier survival analysis showed that, $m i R-21$ and miR-498 overexpression in CRC cases $(n=124)$ associated significantly with reduced DFS $(p=0.006$ and $p<0.001$, respectively, $\log$ rank) and OS $(p=0.001$ and $p=0.006$, respectively, log rank) (Figs. $4 \& 5$ ). Reduced expression of miR-137, miR-145 and miR-320 associated significantly with reduced DFS $(p<0.001, p<0.001$ and $p=0.002$, respectively, log rank) and OS ( $p<0.001$, for all, log rank) (Figs. 4 \& 5).

On multivariate survival analysis adjusted for PS and all studied miRNAs, only $m i R-21$ and $m i R-498$ were independent prognostic factors for inferior OS whereas, $m i R-498$ and $m i R-320$ were independent prognostic factors for DFS (Table 9). High expression of $m i R-21$ and $m i R 498$ increased the hazards of death by more than 2 folds when compared to normal expression whereas $m i R-498$ overexpression and reduced miR-320 expression doubled the hazards of recurrence compared to the normal expression of these markers.

\section{Discussion}

Although there are several studies on the role of miRNAs in CRC from Europe and USA, no single study has been published yet from Egypt or the Middle East. In the current study we assessed the expression levels of five miRNAs $(m i R-21, m i R-137, m i R-145, m i R-320$ and $m i R-498)$ in the blood and tissues of stage II CRC patients from Egypt. These miRNAs were previously mentioned in relation to the development and progression of CRC cases from Europe and USA [4, 6, 7, 13]. 


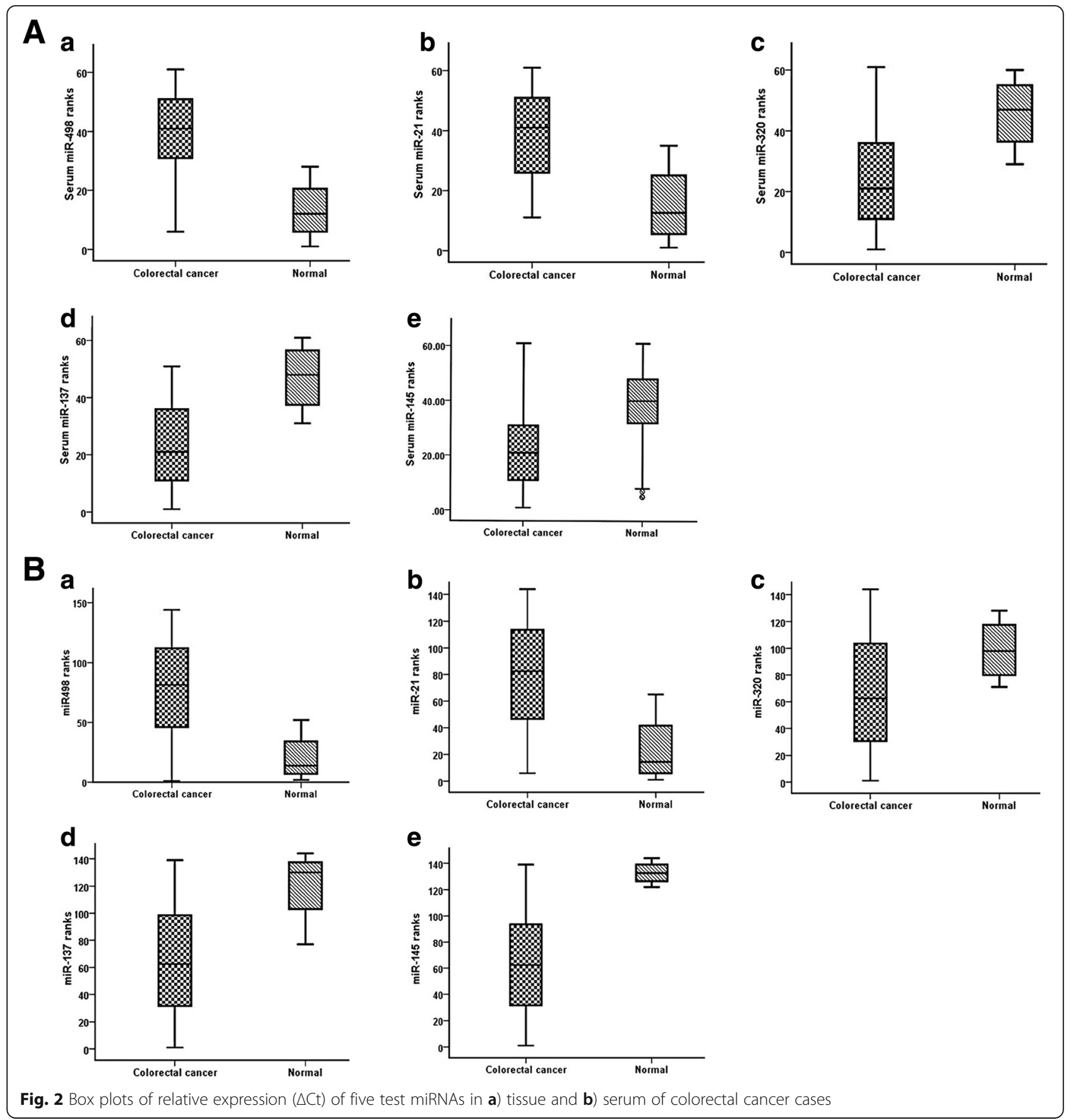

Table 4 Degree of concordance between miRNA expression in tissues and serum samples of colorectal cancer cases

\begin{tabular}{lll}
\hline miRNAs & Measure of agreement (Kappa) & $P$ value \\
\hline miRNA-498 & $69.9 \%$ & $<0.001$ \\
miRNA-21 & $80.2 \%$ & $<0.001$ \\
miRNA -145 & $51 \%$ & 0.001 \\
miRNA -137 & $70.1 \%$ & $<0.001$ \\
miRNA -320 & $41.7 \%$ & 0.006 \\
\hline
\end{tabular}

According to our data, aberrant expression in one or more of the studied miRNAs was present in $71 \%$ and $73.2 \%$ of the CRC tissues and sera; respectively compared to the normal control. miR-21 and miR-498 were significantly over-expressed whereas miR-137, miR-145 and $m i R-320$ were reduced in patients' sera and tissues. Our data in this context are similar to previously published data in literature, except for miR-498 which is down regulated in other studies from USA and Europe $[4,6,7,14]$. 
Table 5 The degree of concordance between the expression levels of different miRNAs in stage II colorectal cancer patients

\begin{tabular}{lll}
\hline miRNA & Measure of agreement (Kappa) & $P$-value \\
\hline miR-498 and miR-21 & $29 \%$ & 0.001 \\
miR-498 and miR-145 & $42.1 \%$ & $<0.001$ \\
miR-498 and miR-137 & $14.3 \%$ & 0.11 \\
miR-498 and miR-320 & $25.6 \%$ & 0.004 \\
miR-21 and miR-145 & $51.6 \%$ & $<0.001$ \\
miR-21 and miR-137 & $50.5 \%$ & $<0.001$ \\
miR-21 and miR-320 & $66.4 \%$ & $<0.001$ \\
miR-145 and miR-137 & $43.9 \%$ & $<0.001$ \\
miR-145 and miR-320 & $53.5 \%$ & $<0.001$ \\
miR-137 and miR-320 & $40.7 \%$ & $<0.001$ \\
\hline
\end{tabular}

Overexpression of $m i R-498$ was reported in $43.9 \%$ of our CRC cases compared to the control group. In contrast, Gopalan et al., [5] showed that, miR-498 was too low to be detected in all CRC cases assessed compared to the non-neoplastic tissues. They concluded that miR498 down regulation in CRC tissues and the direct suppressive cellular effect noted in the tested cancer cell lines suggest direct or indirect role(s) of miR-498 in colon carcinogenesis. Moreover, Schepler [14], proved in their work on 49 cases of stage II CRC with different microsatellite status and recurrence rates that miR-498 and $m i R-320$ could be used as predictive biomarkers, which correlate with recurrence-free survival. The

Table 6 The relative expression of studied miRNA in tissue of recurrent and non-recurrent CRC patients

\begin{tabular}{|c|c|c|c|}
\hline \multirow[t]{2}{*}{ Micro-RNAs } & \multicolumn{2}{|c|}{ CRC stage II patients (124) } & \multirow[t]{2}{*}{ p. values } \\
\hline & Recurrent (45) & Non-recurrent (79) & \\
\hline miRNA-498 & & & $x 2=13.6$ \\
\hline Overexpression & 27 & 23 & $p<0.001$ \\
\hline Normal & 18 & 56 & \\
\hline miRNA-21 & & & $x^{2}=2.5$ \\
\hline Overexpression & 26 & 34 & $p=0.11$ \\
\hline Normal & 19 & 45 & \\
\hline miRNA-145 & & & $x^{2}=5.4$ \\
\hline Reduced expression & 28 & 32 & $p=0.02$ \\
\hline Normal & 17 & 47 & \\
\hline miRNA-137 & & & $x 2=12.4$ \\
\hline Reduced expression & 27 & 22 & $p<0.001$ \\
\hline Normal & 18 & 57 & \\
\hline miRNA-320 & & & $x^{2}=1.6$ \\
\hline Reduced expression & 27 & 38 & $p=0.2$ \\
\hline Normal & 18 & 41 & \\
\hline
\end{tabular}

The data in boldface denotes the presence of statistically significant difference between the studied groups contradiction in the results of the aforementioned studies and the current study could be attributed to 1) racial or population differences, 2) different environmental or dietary factors that may play a role at the epigenetic rather than the genetic level e.g. promoter hypermethylation (PM) which down-regulate or silence the miR-498 expression, 3) the relatively low number of the patients included in the previous studies compared to ours and 4) the different inclusion criteria since we assessed stage II cases only. Hence, it seems difficult to draw a conclusion regarding miR-498 expression in CRC and further studies are still needed. The increase in miR-498 stimulates $F O X O 3$ expression with subsequent down regulation of cyclin-D1 and up-regulation of $p 21 \mathcal{E} p 27$. This will ultimately block cell entry into the SPF of the cell cycle and suppress cell proliferation [15].

$\mathbf{m i R}-\mathbf{2 1}$ is overexpressed in many tumor types including $C R C$ and this overexpression reduces many tumor suppressor genes [8, 16, 17]. Slaby et al., [17] reported significant overexpression of $m i R-21$ relative to the corresponding normal mucosa in 193 CRC patients at different disease stages and Schee et al., [18] showed that $m i R-21$ was the most frequently overexpressed miRNA among six miRNAs (miR-21, miR-31, miR-92a, miR-101, $m i R-106 a$ and miR-145) assessed in their study. They concluded that $m i R-21$ is a biomarker for CRC. Our data confirm the previously mentioned studies since miR-21 was significantly overexpressed in $48.4 \%$ of our tested patients.

On the other hand, $40 \%$ of our tested patients revealed significant reduction in $\mathbf{m i R}-\mathbf{1 3 7}$ compared to the control samples. Similar data were reported by Chen et al., [11] and Balaguer et al., [19]. The later found that miR137 expression was reduced PM in the 6 tested cell lines as well as in $82.3 \%$ of the 41 colonic adenomas and the $81.4 \%$ of the 160 CRCs but in none of the normal tissues. When they transfected the CRC cells with miR-137 precursors, cellular proliferation was inhibited. They concluded that, miR-137 is a tumor suppressor which is inactivated at an early stage in the genetic cascade of the adenoma- carcinoma sequence. Therefore, it could be used for early detection of CRC in high risk individuals with familial adenomatous polyposis (FAP).

The current study is one of the few studies that proved a prognostic value of miR-145 in CRC. miR-145 induces its functions partially via activating the $P A K$ gene, an important oncogene that promotes cellular migration [20]. PAK overexpression associated significantly with aggressive tumor phenotypes and poor prognosis in CRC patients and therefore it represents a new prognostic factor those patients $[10,21-23]$. The anti-tumor effect of miR-145 is achieved via targeting insulin receptor substrate-1, the docking protein of IGF1-R, with consequent inhibition of IGF1-R signaling in CRC [24]. This has been confirmed in 
Table 7 The associations between the relevant clinic-pathological features of stage II CRC patients and disease free survival

\begin{tabular}{|c|c|c|c|c|c|c|c|c|}
\hline \multirow[t]{2}{*}{ Factors } & \multirow[t]{2}{*}{$N=124(\%)$} & \multicolumn{5}{|c|}{ Disease free survival \% } & \multirow{2}{*}{$\begin{array}{l}\text { Median months } \\
(95 \% \mathrm{Cl})\end{array}$} & \multirow{2}{*}{$\begin{array}{l}\text { Log rank } \\
P \text { value }\end{array}$} \\
\hline & & $1 \mathrm{yr}$ & $2 \mathrm{yrs}$ & 3 yrs & $5 \mathrm{yrs}$ & $10 \mathrm{yrs}$ & & \\
\hline All & $124(100)$ & 81.2 & 67.4 & 62.1 & 60.2 & 45.6 & 72.0 & NA \\
\hline \multicolumn{9}{|l|}{ Age (yrs) } \\
\hline$\leq 45$ & $60(48.4)$ & 81.3 & 69.4 & 64.2 & 64.2 & 40.1 & $66(52-79)$ & 0.917 \\
\hline$>45$ & $64(51.6)$ & 81.1 & 65.4 & 60.3 & 55.4 & 47.7 & 103 & \\
\hline \multicolumn{9}{|l|}{ Gender } \\
\hline Male & $64(51.6)$ & 76.2 & 63.0 & 60.3 & 60.3 & 41.4 & $72(4-139)$ & 0.41 \\
\hline Female & $60(48.4)$ & 86.4 & 72.1 & 63.8 & 59.3 & 51.9 & NA & \\
\hline \multicolumn{9}{|l|}{ Residence } \\
\hline Urban & $66(53.2)$ & 86.0 & 71.3 & 64.5 & 64.5 & 54.5 & NA & 0.225 \\
\hline Rural & $58(48.4)$ & 81.0 & 63.0 & 59.9 & 55.3 & NA & $62(21-102)$ & \\
\hline \multicolumn{9}{|l|}{ DM } \\
\hline -ve & $109(87.9)$ & 81.3 & 67.5 & 64.4 & 62.3 & 47.2 & 103 & 0.414 \\
\hline+ ve & $15(12.1)$ & 80.0 & 66.7 & 44.4 & NA & NA & 30 (21-38) & \\
\hline \multicolumn{9}{|l|}{ HTN } \\
\hline -ve & $110(88.7)$ & 81.7 & 67.1 & 61.1 & 58.9 & 41.9 & $72(14.8-129.1)$ & 0.434 \\
\hline+ ve & $14(11.3)$ & 76.9 & 69.2 & 69.2 & 69.2 & 69.2 & NA & \\
\hline \multicolumn{9}{|l|}{ Family history } \\
\hline -ve & $103(83.1)$ & 79.2 & 65.9 & 61.3 & 59.0 & 44.6 & $103(28.2-177.5)$ & 0.804 \\
\hline+ ve & $21(16.9)$ & 90.5 & 73.5 & 65.3 & 65.3 & 49.0 & NA & \\
\hline \multicolumn{9}{|l|}{ Smoking } \\
\hline -ve & $88(71)$ & 94.4 & 75.6 & 73.4 & 70.2 & 53.0 & NA & 0.078 \\
\hline$+v e$ & $36(29)$ & 74.3 & 57.0 & 52.6 & 52.6 & 39.5 & $103(0-225)$ & \\
\hline \multicolumn{9}{|l|}{ PS } \\
\hline 0 & $56(45.2)$ & 89.3 & 81.7 & 79.2 & 75.5 & 51.0 & NA & 0.016 \\
\hline I & $48(38.7)$ & 76.6 & 56.6 & 49.0 & 49.0 & 49.0 & 32 & \\
\hline$\|$ & $20(16.1)$ & 68.6 & 52.3 & 43.5 & 43.5 & NA & $30(8.1-51.9)$ & \\
\hline \multicolumn{9}{|l|}{ Pathology } \\
\hline Adenocarcinoma & $105(84.7)$ & 82.5 & 68.5 & 62.3 & 60.2 & 47.5 & 72 & 0.713 \\
\hline Mucinous & $19(15.3)$ & 73.7 & 61.4 & 61.4 & 61.4 & 40.6 & $103(0-249)$ & \\
\hline \multicolumn{9}{|l|}{ Grade } \\
\hline$|-| \mid$ & 109 (87.9) & 81.3 & 68.7 & 64.2 & 62.1 & 46.4 & 102 & 0.425 \\
\hline III & $15(12.1)$ & 80.0 & 58.7 & 46.9 & 46.9 & NA & 32 & \\
\hline \multicolumn{9}{|l|}{ T. stage } \\
\hline $\mathrm{T} 3$ & $84(67.7)$ & 85.4 & 76.7 & 69.5 & 66.8 & 45.9 & 103 & 0.058 \\
\hline $\mathrm{T} 4$ & $40(32.3)$ & 75.0 & 46.0 & 46.0 & 46.0 & 46.0 & 21 & \\
\hline \multicolumn{9}{|l|}{ Dissected LN } \\
\hline$<12$ & $60(48.4)$ & 81.7 & 69.5 & 64.5 & 60.9 & 44.3 & $66(49.7-82.2)$ & 0.89 \\
\hline$\geq 12$ & $64(51.6)$ & 80.7 & 65.4 & 60.2 & 60.2 & 48.1 & 103 & \\
\hline \multicolumn{9}{|l|}{ Adjuvant } \\
\hline No & $30(24.2)$ & 88.6 & 70.8 & 61.0 & 54.2 & 54.2 & NA & 0.787 \\
\hline Yes & $94(75.8)$ & 79.4 & 66.4 & 61.1 & 61.1 & 43.4 & $72(25.3-118.7)$ & \\
\hline
\end{tabular}

The data in boldface denotes the presence of statistically significant difference between the studied groups 
Table 8 The correlation between clinico-pathological features of the patients and disease free survival

\begin{tabular}{|c|c|c|c|c|c|c|c|c|}
\hline \multirow[t]{2}{*}{ Factors } & \multirow[t]{2}{*}{$N=124(\%)$} & \multicolumn{5}{|c|}{ Disease free survival \% } & \multirow{2}{*}{$\begin{array}{l}\text { Median months } \\
\text { (95\% Cl) }\end{array}$} & \multirow{2}{*}{$\begin{array}{l}\text { Log rank } \\
P \text { value }\end{array}$} \\
\hline & & $1 \mathrm{yr}$ & $2 \mathrm{yrs}$ & 3 yrs & $5 \mathrm{yrs}$ & $10 \mathrm{yrs}$ & & \\
\hline All & $124(100)$ & 91.0 & 76.1 & 72.4 & 69.1 & 56.5 & NA & NA \\
\hline \multicolumn{9}{|l|}{ Age (yrs) } \\
\hline$\leq 48$ & $65(52.4)$ & 93.8 & 78.1 & 75.9 & 75.9 & 56.9 & NA & 0.412 \\
\hline$>48$ & $59(47.6)$ & 88.0 & 73.9 & 68.8 & 63.0 & 56.7 & NA & \\
\hline \multicolumn{9}{|l|}{ Gender } \\
\hline Male & $64(51.6)$ & 88.9 & 73.8 & 70.0 & 70.0 & 55.7 & NA & 0.593 \\
\hline Female & $60(48.4)$ & 93.2 & 78.7 & 75.3 & 67.7 & 58.1 & NA & \\
\hline \multicolumn{9}{|l|}{ Residence } \\
\hline Urban & $66(53.2)$ & 92.2 & 79.1 & 72.3 & 72.3 & 67.1 & NA & 0.343 \\
\hline Rural & $58(48.4)$ & 89.7 & 72.9 & 73.9 & 58.3 & NA & $75(39.7-110.2)$ & \\
\hline \multicolumn{9}{|l|}{ DM } \\
\hline -ve & $109(87.9)$ & 91.6 & 76.6 & 74.2 & 70.8 & 57.9 & NA & 0.486 \\
\hline+ ve & $15(12.1)$ & 86.7 & 72.7 & 54.4 & NA & NA & NA & \\
\hline \multicolumn{9}{|l|}{ HTN } \\
\hline -ve & $110(88.7)$ & 89.9 & 77.0 & 72.7 & 68.9 & 54.3 & NA & 0.99 \\
\hline+ ve & $14(11.3)$ & 100 & 69.2 & 69.2 & 69.2 & 69.2 & NA & \\
\hline \multicolumn{9}{|l|}{ Family history } \\
\hline -ve & $103(83.1)$ & 89.1 & 74.5 & 72.0 & 68.0 & 56.8 & NA & 0.508 \\
\hline+ ve & $21(16.9)$ & 100 & 83.2 & 71.3 & 71.3 & 53.3 & NA & \\
\hline \multicolumn{9}{|l|}{ Smoking } \\
\hline -ve & $88(71)$ & 94.4 & 78.9 & 78.9 & 74.5 & 54.2 & NA & 0.741 \\
\hline+ ve & $36(29)$ & 88.6 & 73.7 & 70.5 & 70.5 & 70.5 & NA & \\
\hline \multicolumn{9}{|l|}{ PS } \\
\hline 0 & $56(45.2)$ & 94.6 & 86.6 & 86.6 & 81.0 & 66.0 & NA & 0.005 \\
\hline 1 & $48(38.7)$ & 89.4 & 68.9 & 65.9 & 65.9 & 52.7 & NA & \\
\hline$\|$ & $20(16.1)$ & 84.4 & 62.2 & 40.8 & 40.8 & NA & $34(16.2-51.8)$ & \\
\hline \multicolumn{9}{|l|}{ Pathology } \\
\hline Adenocarcinoma & $105(84.7)$ & 90.3 & 73.8 & 70.6 & 66.9 & 51.9 & NA & 0.205 \\
\hline Mucinous adenocarcinoma & $19(15.3)$ & 94.7 & 89.5 & 82.6 & 82.6 & 82.6 & NA & \\
\hline \multicolumn{9}{|l|}{ Grade } \\
\hline $\mid-H$ & $109(87.9)$ & 90.7 & 76.0 & 72.9 & 69.4 & 56.3 & NA & 0.919 \\
\hline III-IV & $15(12.1)$ & 93.3 & 76.0 & 67.9 & 67.9 & NA & NA & \\
\hline \multicolumn{9}{|l|}{ T.stage } \\
\hline $\mathrm{T} 3$ & $84(67.7)$ & 92.7 & 83.3 & 80.1 & 75.3 & 56.9 & NA & NA \\
\hline $\mathrm{T} 4$ & $32(25.8)$ & 87.5 & 55.9 & 51.6 & 51.6 & 51.6 & NA & \\
\hline Missed & $8(6.4)$ & & & & & & & \\
\hline \multicolumn{9}{|l|}{ Dissected LN } \\
\hline$<12$ & $60(48.4)$ & 90.0 & 79.3 & 73.6 & 67.9 & 51.4 & NA & 0.79 \\
\hline$\geq 12$ & $64(51.6)$ & 92.0 & 73.1 & 70.9 & 70.9 & 62.0 & NA & \\
\hline \multicolumn{9}{|l|}{ Adjuvant } \\
\hline No & $30(24.2)$ & 91.4 & 82.8 & 79.3 & 63.4 & 47.6 & 75.0 & 0.697 \\
\hline Yes & $94(75.8)$ & 91.3 & 74.7 & 71.0 & 71.0 & 60.4 & NA & \\
\hline \multicolumn{9}{|l|}{ Toxicity } \\
\hline No & $70(56.5)$ & 88.4 & 77.8 & 70.0 & 56.0 & 42.0 & $75.0(32.9-117.2)$ & 0.386 \\
\hline Yes & $54(43.5)$ & 94.4 & 74.3 & 74.3 & 74.3 & 63.2 & NA & \\
\hline
\end{tabular}

The data in boldface denotes the presence of statistically significant difference between the studied groups 

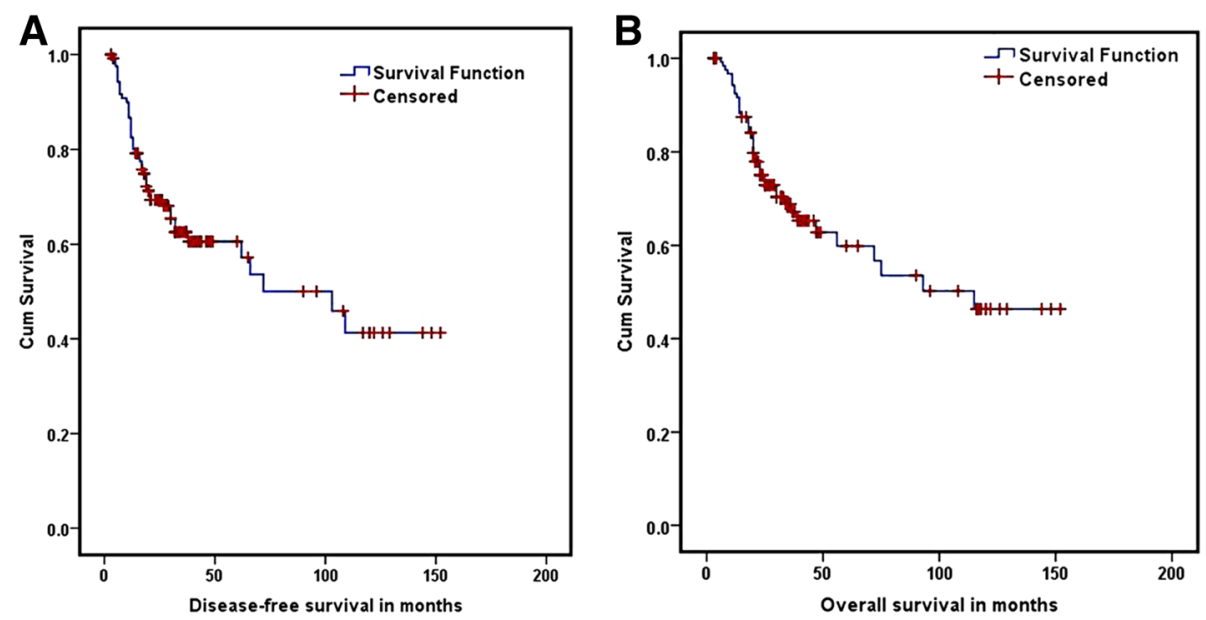

Fig. 3 Kaplan-Meier survival curves for disease free survival (DFS) and overall survival (OS) in the whole group of colorectal cancer patients. a: disease free survival (DFS) curve for the total CRC patients, b: overall survival (OS) curve for the total CRC patients
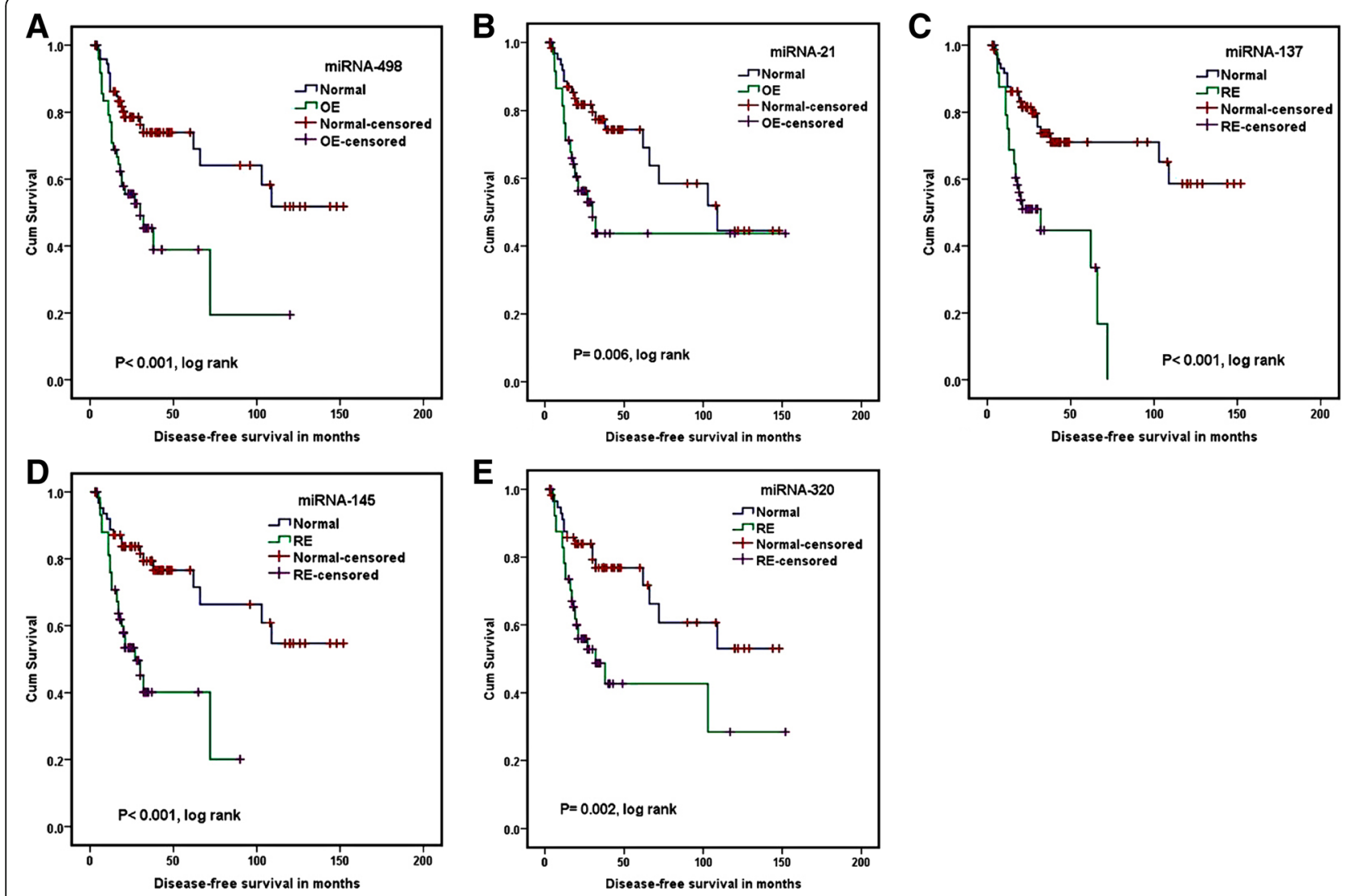

Fig. 4 Kaplan-Meier survival curves for disease free survival (DFS) in CRC patients according to the studied miRNAs. a: disease free survival for CRC patients according to miR-498, b: disease free survival for CRC patients according to miR-21, $\mathbf{c}$ : disease free survival for CRC patients according to miR-137, d: disease free survival for CRC patients according to miR-145 and e: disease free survival for CRC patients according to miR-320. (RE: reduced expression, OE: overexpression) 


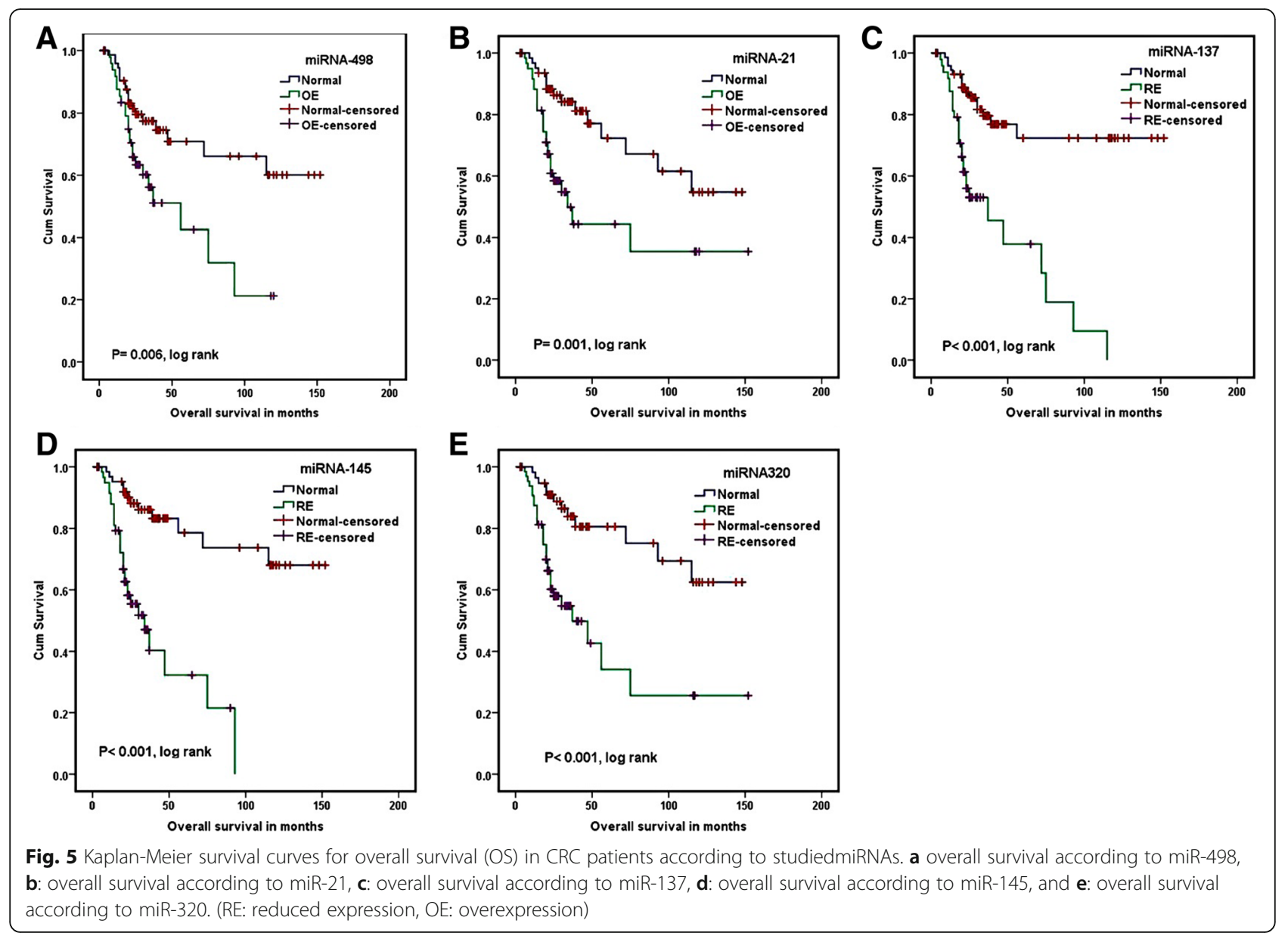

a larger study performed on 49 stage-II CRC cases using 315 human miRNAs (including miR-145 and $m i R-320$ ). According to the results of this study, miR-145 showed the lowest expression level in cancerous tissues followed by $m i R-320$. The later acts through inactivating the $\mathrm{Wnt} / \beta$-catenin pathway in CRC cells via targeting FOXM1 and other important molecular pathways e.g. cell proliferation \&

Table 9 Multivariate survival analysis for DFS and OS in stage ॥ CRC patients

\begin{tabular}{|c|c|c|c|c|c|c|}
\hline \multirow[t]{2}{*}{ Parameters } & \multicolumn{3}{|c|}{ Disease-free survival } & \multicolumn{3}{|c|}{ Overall survival } \\
\hline & $\overline{\mathrm{HR}}$ & $95 \% \mathrm{Cl}$ & $P$ value & $\overline{\mathrm{HR}}$ & $95 \% \mathrm{Cl}$ & $P$ value \\
\hline PS 0 and I vs II & 1.28 & $0.85-1.9$ & 0.23 & 1.35 & $0.87-2.12$ & 0.19 \\
\hline T.stage T3vs T4 & & & & 1.6 & $0.84-2.9$ & 0.16 \\
\hline miR-498OE vs normal & 2.2 & $1.2-4.1$ & 0.01 & 2.2 & $1.1-4.7$ & 0.033 \\
\hline miR-21OE vs normal & 0.9 & $0.34-1.66$ & 0.48 & 2.8 & $1.3-6.1$ & 0.012 \\
\hline miR-137 RE vs normal & 1.9 & $0.87-4.2$ & 0.11 & 1.1 & $0.4-2.16$ & 0.8 \\
\hline miR-145 RE vs normal & 1.6 & $0.73-3.6$ & 0.24 & 1.17 & $0.56-2.4$ & 0.67 \\
\hline miR-320RE vs normal & 2 & $1.1-3.9$ & 0.029 & 1.9 & $0.8-4.6$ & 0.14 \\
\hline
\end{tabular}

$H R$ hazard ratio, $O E$ over expression, $R E$ reduced expression

The data in boldface denotes the presence of statistically significant difference between the studied groups migration, invasion, apoptosis, angiogenesis, inflammation and epithelial-mesenchymal transition (EMT). Thus, down regulation of $m i R-320$ is also considered a poor prognostic factor [25].

In univariate analysis, aberrant expression of all tested miRNAs associated significantly with higher incidence of recurrence and lower survival rates. Our data regarding the correlation between miR-21 overexpression and survival (DFS\&OS) are in accordance with some previous studies [19, 26, 27], however none of these studies was done on stage II cases only.

In this context Schepeler et al., [14] demonstrated that aberrant $m i R-320$ and $m i R-498$ expression associated significantly with higher incidence of recurrence and decreased DFS suggesting that both of them can be used to predict recurrence in stage II CRC patients with high accuracy (an overall performance accuracy of $81 \%$ ). Similarly, reduced miR-137 expression associated significantly with CRC progression and metastasis, especially to the liver, and thus it could be used as a prognostic factor in this disease. 0n the other hand, in multivariate Cox regression analysis, aberrant expression of $m i R-21, m i R-137$ and $m i R-498$ were independent prognostic factors for inferior 
OS while miR-320 and miR-498 were independent prognostic factors for reduced DFS. Our data regarding $m i R-320$ and miR-498are in agreement with those of Schepeler et al., [14] who also reported that miR-320 and miR-498 could be used to predict tumor recurrence and reduced DFS in stage II CRC patients.

Similar to previously published data we found that CRC patients overexpressing miR-21 have significantly reduced DFS and OS rates. In this context, Schetter et al., [13], and Nielsen et al., [28] reported significant association between aberrant miR-21 expression and reduced survival rates independent of other clinical parameters. Another study by Oue et al., [29], confirmed these in univariate and multivariate analysis.

An important finding in the current study is the concordance in the data of serum and tissue samples. This concordance denotes that circulating miRNAs could be used as sensitive diagnostic, prognostic or predictive biomarkers as well as for early detection of [30]. In the current study, concordance between serum and tissues was strong for $m i R-21$ and $m i R-137$, intermediate for $m i R-498$ but weak for $m i R-145$ and $m i R-320$. There is a number of factors that might affect the concordance between serum and tissue including 1) the miRNAs may be subjected to degradation in blood, especially after removal of tumors, 2) the effect of treatment given to the patients prior to sampling (blood samples were drawn after chemo-radiotherapy in patients with rectal cancer), 3) the small number of patients assessed in blood and tissues (only 41) compared to 124 for tissues only 4) the short follow-up period in those patients compared to the patients in the retrospective group and 5) the effect of formalin fixation which affect the stability of miRNAs used for qRT-PCR analysis. Therefore, the data of the current study regarding the concordance between serum and tissues needs to be verified in another study including an equal number of patients in each group (serum \& tissue groups).

\section{Conclusions}

We conclude that miR-21, miR-137, miR-145, miR-320 and miR-498 represent highly specific cancer biomarkers that can be used as promising prognostic and predictive biomarkers for stage-II CRC patients on chemoradiotherapy. The relative concordance between the results of miRNAs in serum (circulating miRNAs) and tissues are encouraging since it provides a non-invasive prognostic tool for risk stratification of those patients. This may also open avenues for early detection and personalized therapy for CRC patients. However future large scale prospective studies are still required to settle this issue. According to our data, a panel of three miRNAs $(m i R-21, m i R-498$, and $m i R-320)$ can predict recurrence in stage II CRC patients and a panel of 2 miRNAs (miR-21, $m i R-498)$ can predict survival in those patients.

\section{Acknowledgements}

The authors of the manuscript would like to acknowledge and thank Dr. Ahmad Malya, Ass lecturer of Virology\& Immunology, Cancer Biology Dept., $\mathrm{NCl}$, Cairo University for his help and assistance in revising the manuscript and enhancing the artwork of the manuscript according to the instructions of the editorial office.

\section{Funding}

The funding for the research was provided by the National cancer Institute $(\mathrm{NCl})$, Cairo University. The funding body was used for the collection, analysis, and interpretation of data and in writing the manuscript (Grant no:33,651-15).

\section{Availability of data and materials}

Please contact author for data requests.

\section{Authors' contributions}

$A A B$ designed the study, supervised molecular testing and drafted the manuscript. MES Collected the patients' samples and clinical data of the and followed-up the patients included in the study. NMA Helped in designing the study and supervised the Medical oncology team. OK Assessment and follow up of patients, analysis of the clinical data. MMH Assessment and follow up of patients. HFY Performed the molecular testing of the miRNAs. MAM statistical analysis of the data. ARNZ Supervised and analysed the emerging molecular data and revised the manuscript. SES designed the study, supervised medical oncology team, analyzed the clinical data and helped in drafting the manuscript. All authors read and approved the final manuscript.

\section{Ethics approval and consent to participate}

The study protocol was approved by the Ethical Committee of The National Cancer Institute (NCI), Cairo University, Cairo, Egypt (no:33,651-15) and all participants (patients) signed a written informed consent showing their acceptance to participate in the study.

Consent for publication

Not applicable.

\section{Competing interests}

The authors declare that they have no competing interests.

\section{Publisher's Note}

Springer Nature remains neutral with regard to jurisdictional claims in published maps and institutional affiliations.

Received: 4 May 2017 Accepted: 10 September 2017 Published online: 16 November 2017

References

1. Ferlay J, et al. GLOBOCAN 2012 v1.0, Cancer Incidence and Mortality Worldwide: IARC CancerBase No. 11 [online]. Lyon (France): International Agency for Research on Cancer; 2013. Available from WWW: http:// globocan.iarc.fr

2. Xi Y, et al. Systematic analysis of microRNA expression of RNA extracted from fresh frozen and formalin-fixed paraffin-embedded samples. RNA. 2007;13(10):1668-74

3. Meng W, et al. Comparison of microRNA deep sequencing of matched formalin-fixed paraffin-embedded and fresh frozen cancer tissues. PLoS One. 2013;8(5):e64393.

4. Bandopadhyay $M$, et al. Tumor suppressor micro RNA miR-145 and onco micro RNAs miR-21 and miR-222 expressions are differentially modulated by hepatitis $B$ virus X protein in malignant hepatocytes. BMC Cancer. 2014;14:721.

5. Gopalan $\vee$, Smith RA, Lam AK. Downregulation of microRNA-498 in colorectal cancers and its cellular effects. Exp Cell Res. 2015;330(2):423-8.

6. Santarpia $L$, et al. A miRNA signature associated with human metastatic medullary thyroid carcinoma. Endocr Relat Cancer. 2013;20(6):809-23.

7. Sun $\mathrm{G}$, et al. Overexpressed miRNA-137 inhibits human glioma cells growth by targeting Rac1. Cancer Biother Radiopharm. 2013;28(4):327-34. 
8. Asangani IA, et al. MicroRNA-21 (miR-21) post-transcriptionally downregulates tumor suppressor Pdcd4 and stimulates invasion, intravasation and metastasis in colorectal cancer. Oncogene. 2008;27(15):2128-36.

9. Shi B, et al. Micro RNA 145 targets the insulin receptor substrate-1 and inhibits the growth of colon cancer cells. J Biol Chem. 2007;282(45): 32582-90.

10. Sheng $\mathrm{N}$, et al. MiR-145 inhibits human colorectal cancer cell migration and invasion via PAK4-dependent pathway. Cancer Med. 2017;6(6):1331-40.

11. Chen T, et al. Mecp2-mediated Epigenetic Silencing of miR-137 Contributes to Colorectal Adenoma-Carcinoma Sequence and Tumor Progression via Relieving the Suppression of c-Met. Sci Rep. 2017;7:44543-51.

12. Vishnubalaji R, et al. MicroRNA-320 suppresses colorectal cancer by targeting SOX4, FOXM1, and FOXQ1. Oncotarget. 2016;7(24):35789-802.

13. Schetter AJ, et al. MicroRNA expression profiles associated with prognosis and therapeutic outcome in colon adenocarcinoma. JAMA. 2008;299(4):42536.

14. Schepeler T, et al. Diagnostic and prognostic microRNAs in stage II colon cancer. Cancer Res. 2008;68(15):6416-24.

15. Liu R, et al. MiR-498 regulated FOXO3 expression and inhibited the proliferation of human ovarian cancer cells. Biomed Pharmacother. 2015;72: $52-7$.

16. Volinia S, et al. A microRNA expression signature of human solid tumors defines cancer gene targets. Proc Natl Acad Sci U S A. 2006;103(7):2257-61.

17. Slaby $\mathrm{O}$, et al. Altered expression of miR-21, miR-31, miR-143 and miR-145 is related to clinicopathologic features of colorectal cancer. Oncology. 2007; 72(5-6):397-402.

18. Schee $K$, et al. Clinical relevance of microRNA miR-21, miR-31, miR-92a, miR101, miR-106a and miR-145 in colorectal cancer. BMC Cancer. 2012;12:505.

19. Balaguer $F$, et al. Epigenetic silencing of miR-137 is an early event in colorectal carcinogenesis. Cancer Res. 2010;70(16):6609-18.

20. Wang $Z$, et al. MiR-145 regulates PAK4 via the MAPK pathway and exhibits an antitumor effect in human colon cells. Biochem Biophys Res Commun. 2012;427(3):444-9.

21. Akao Y, Nakagawa Y, Naoe T. MicroRNAs 143 and 145 are possible common onco-microRNAs in human cancers. Oncol Rep. 2006;16(4):845-50.

22. Bandrés $E$, et al. Identification by Real-time PCR of 13 mature microRNAs differentially expressed in colorectal cancer and non-tumoral tissues. Mol Cancer. 2006;5(1):29.

23. Feng $Y$, et al. MicroRNA-145 inhibits tumour growth and metastasis in colorectal cancer by targeting fascin-1. Br J Cancer. 2014;110(9):2300. 9

24. La Rocca G, et al. Mechanism of growth inhibition by MicroRNA 145: the role of the IGF-I receptor signaling pathway. J Cell Physiol. 2009;220(2):48591.

25. Wan $L Y$, et al. miR-320 enhances the sensitivity of human colon cancer cells to chemoradiotherapy in vitro by targeting FOXM1. Biochem Biophys Res Commun. 2015:457(2):125-32.

26. Xia X, et al. Prognostic role of microRNA-21 in colorectal cancer: a metaanalysis. PLoS One. 2013;8(11):e80426.

27. Kang WK, et al. Stromal expression of miR-21 in T3-4a colorectal cancer is an independent predictor of early tumor relapse. BMC Gastroenterol. 2015; $15: 2$.

28. Nielsen BS, et al. High levels of microRNA-21 in the stroma of colorectal cancers predict short disease-free survival in stage II colon cancer patients. Clin Exp Metastasis. 2011;28(1):27-38.

29. Oue N, et al. High miR-21 expression from FFPE tissues is associated with poor survival and response to adjuvant chemotherapy in colon cancer. Int J Cancer. 2014;134(8):1926-34.

30. Ng EK, et al. Differential expression of microRNAs in plasma of patients with colorectal cancer: a potential marker for colorectal cancer screening. Gut. 2009;58(10):1375-81.

\section{Submit your next manuscript to BioMed Central and we will help you at every step:}

- We accept pre-submission inquiries

- Our selector tool helps you to find the most relevant journal

- We provide round the clock customer support

- Convenient online submission

- Thorough peer review

- Inclusion in PubMed and all major indexing services

- Maximum visibility for your research

Submit your manuscript at www.biomedcentral.com/submit
Biomed Central 